\title{
SPeCIAL IsSUE: \\ Remote Sensing Applications for Investigations of Fire Regime Attributes
}

Fire is a primary change agent in many terrestrial ecosystems. Appreciation is growing for the essential role fire plays in fire-adapted ecosystems. Nevertheless, humans living in the wildland urban interface (WUI) understandably regard fires as a threat to their safety, their property, or the natural resources and ecosystem services upon which they depend. As land development has expanded into the WUI, so has the demand for better spatial information regarding fire danger and fire effects, both short- and long-term.

Remote sensing has become essential for mapping: 1) wildland fire perimeters, 2) the area burned within the perimeter, and 3) the variability and severity of ecological effects on vegetation and soils within the area burned. The current state of post-fire remote sensing applications is either directly described or exemplified by several applications in this compilation of eight articles for this special issue of Fire Ecology. These papers originated from oral presentations delivered at the 3rd International Fire Ecology and Management Congress, held in San Diego, California, 13-17 November 2006.

Starting things off are Eidenshink et al., who upon our special request describe the Monitoring Trends in Burn Severity (MTBS) project, which over the course of six years will map the fire severity of all large fires in the United States from 1984 until 2010. This is a tremendous undertaking expected to document the perimeters and severity using the differenced Normalized Burn Ratio (dNBR) on over 9000 large fires, and will constitute an invaluable resource for a broad spectrum of research applications and management needs at the national, regional, state, and local levels for years to come. In addition, the MTBS project will facilitate monitoring the effectiveness of fuel treatment activities.

In the first applications paper of this special issue, Kolden and Weisberg provide some justification for the MTBS project. They compared the accuracy of wildfire perimeters delineated from Landsat-derived dNBR imagery to perimeters mapped using traditional manual methods, for 53 fires in northern Nevada, USA. They quantify the significant disparity in perimeter accuracies, particularly in rough terrain and discuss the problems associated with using fire perimeter datasets comprised of both satellite-derived and manually mapped perimeters.

A compilation of perimeters or burn area maps can be used to explore the spatial and temporal characteristics of variable fire regimes, as determined by differing land covers and land uses. In Australia, Petty and Bowman apply MODIS imagery to compare the high yet contrasting fire frequencies of three alternative management regimes in the Northern Territory, Australia. RussellSmith et al. consider the heterogeneity in both the fire season and severity aspects of fire regime across the whole of Australia. These studies illustrate the influence fire regime has on fire patterns in space and time over vast regions, as can be characterized only by remote sensing.

Fire severity is defined as the magnitude of the ecological effect of fire on vegetation and soils. While particular fire effects can be measured in the field, fire severity typically is characterized remotely using the dNBR or similar fire severity indices, usually derived from Landsat Thematic Mapper (TM) or Enhanced Thematic Mapper (ETM+) imagery. Hudak et al. report on the strength 
of relationships between several image-derived fire severity indices and individual measures of fire effects on vegetation and soils, from field plots characterized in three different ecosystems across North America. Lentile et al. report on vegetation responses observed at these same plots spanning the full range of fire severities observed, and the different patch sizes of the fire severity classes for the three ecosystems sampled. In southern California, Lewis et al. focus on soil effects, and compare the utility of fire severity indices derived from Landsat to estimates of soil erosion potential and hydrological response derived from hyperspectral imagery.

The final paper by Chuvieco et al. acknowledges the laborious nature of field validation studies of fire severity like the three just exemplified, and presents a radiative transfer modeling approach to assessing the sources of variability in observed spectral response. The simulated scenarios are based on the broadly applied Composite Burn Index (CBI) field measure of fire severity, which in this case was collected from a single large fire in Spain, and used both Landsat and MODIS imagery.

This special issue compilation of eight papers demonstrates the breadth of remote sensing applications on the cutting edge of fire ecology research. Remotely sensed imagery can provide objective measures of fire perimeters, burn patterns, and fire severity at large spatial and temporal scales that would be virtually impossible to characterize by other means on the ground. Remote sensing data can add value to field data for improved maps, and used in modeling studies to better understand ecological processes, to the benefit of both fire ecologists and managers.

Andrew T. Hudak

Forest Service, U.S. Department of Agriculture

Rocky Mountain Research Station

Forestry Sciences Laboratory

1221 South Main Street

Moscow, ID 83843

Andrea E. Thode

School of Forestry

South San Francisco Street

University of Northern Arizona

Flagstaff, AZ 86011

Jan W. van Wagtendonk

USGS Western Ecological Research Center

Yosemite Field Station

El Portal, CA 95318 